\title{
THE CONCEPTUAL FRAMEWORK TO ACHIEVE ENERGY CONSUMPTION BALANCE IN KUALA LUMPUR SHOPHOUSES FOR MITIGATING URBAN HEAT ISLAND EFFECTS WITH FOCUSING ON ANTHROPOGENIC HEAT FACTOR
}

\author{
P. Shahmohamadi ${ }^{1}$, A.I. Che-Ani ${ }^{1 *}$, N.M. Tawil ${ }^{1}$, K.N.A. Maulud ${ }^{1}$, M.M. Tahir ${ }^{1}$ \\ ${ }^{1}$ Faculty of Engineering and Built Environment, Universiti Kebangsaan Malaysia \\ *adiirfan@gmail.com
}

\begin{abstract}
Shophouses represent important land uses in Kuala Lumpur since many years ago, which influence the resulting thermal environment including the formation of urban heat island (UHI). Production of anthropogenic heat and using energy for cooling systems, lighting and etc. in shophouses led to have serious impacts on the thermal environmental quality such as quality of the air, increase in temperature, energy consumption and finally the formation of UHI. An attempt to study and observe the problems of Kuala Lumpur shophouses has been made, using conceptual framework to understand the correlation among increasing the intensity of UHI, the production of anthropogenic heat and energy consumption. This paper literately investigates the impact of Urban Heat Island (UHI) on energy consumption and also determines which factors can directly affect energy use in shophouses with focus on anthropogenic heat factor and finally suggests three important strategies to minimise the impact of UHI on energy consumption: promoting natural ventilation of shophouses, using appropriate materials on external surfaces and providing appropriate greenery.
\end{abstract}

Keywords: Anthropogenic Heat, Energy Consumption Balance, Kuala Lumpur Shophouses, Urban Heat Island.

\section{Introduction}

Building itself is related to global changes in the increase of urban temperatures, the rate of energy consumption, the increased use of raw materials, pollution and the production of waste, conversion of agricultural to developed land, loss of biodiversity, and water shortages (Santamouris et al., 2001). It is clear that buildings without high climatic quality in urban areas use more energy for air conditioning and even more electricity for lighting. Moreover, discomfort and inconvenience to the urban population due to high temperatures, wind tunnel effects in streets and unusual wind turbulence due to incorrectly used of energy is very common.

With the concentration of anthropogenic activities into urban areas, a climatic environmental problem, the "urban heat island" (UHI), has emerged. An UHI is a climatic phenomenon in which urban areas have higher air temperature than their rural surroundings as a result of anthropogenic modifications of land surfaces, significant energy use, and its consequent generation of waste heat. Thus, this might prove to be an unsustainable factor that leads to excessive energy use for cooling and putting the urban population at great risk for morbidity and mortality. According to the above perspective and considering that rapid and huge population growth is expected in the near 
future, it becomes increasingly important to apply UHI mitigation strategies in order to reduce energy consumption and improve the quality of life with focusing on energy consumption in Shophouses in Kuala Lumpur.

Thus, this paper investigates the primary factors of UHI formation, such as anthropogenic heat, which significantly use more energy. Then, according to the Oke's energy balance concept that shows that all of the energy absorbed by the surface through radiation or from anthropogenic heat goes somewhere and warms the air above the surface, is evaporated away with moisture or is stored in the material as heat. Since shophouses in Kuala Lumpur, as mix used buildings, use more energy for cooling buildings produce higher anthropogenic heat lead to UHI intensity and alienate energy consumption balance. For energy saving, therefore, this paper suggests some strategies to provide the best possible energy saving solution.

\section{Urban Heat Island}

The majority of cities are sources of heat and pollution, and the thermal structure of the atmosphere above them is affected by the "heat island" effect. A UHI is best visualised as a dome of stagnant warm air over the heavily built-up areas of cities (Emmanuel, 2005). The heat that is absorbed during the day by the buildings, roads and other constructions in an urban area is re-emitted after sunset, creating high temperature differences between urban and rural areas (Asimakopoulos et al., 2001). The exact form and size of this phenomenon varies in time and space as a result of meteorological, regional and urban characteristics (Oke, 1987). Therefore, UHI morphology is greatly influenced by the unique character of each city and its land uses. As seen in Figure 1, Oke (1987) stated that in a larger city with a cloudless sky and light winds just after sunset, the boundary between the rural and the urban areas exhibits a steep temperature gradient to the UHI, and then the rest of the urban area appears as a "plateau" of warm air with a steady but weaker horizontal gradient of increasing temperature towards the city centre. In Figure 1, the uniformity of the "plateau" is interrupted by the influence of distinct intra-urban land-uses such as parks, lakes and open areas (cool), and commercial, industrial or dense building areas (warm).

In metropolitan areas, the urban core shows a final "peak" in the UHI where the urban maximum temperature is

found. The difference between this value and the background rural temperature defines the "UHI intensity" $\left({ }^{\Delta T_{u-r}}\right)$. The intensity of the UHI is mainly determined by the thermal balance of the urban region and can result in a temperature difference of up to 10 degrees (Asimakopoulos et al., 2001). 


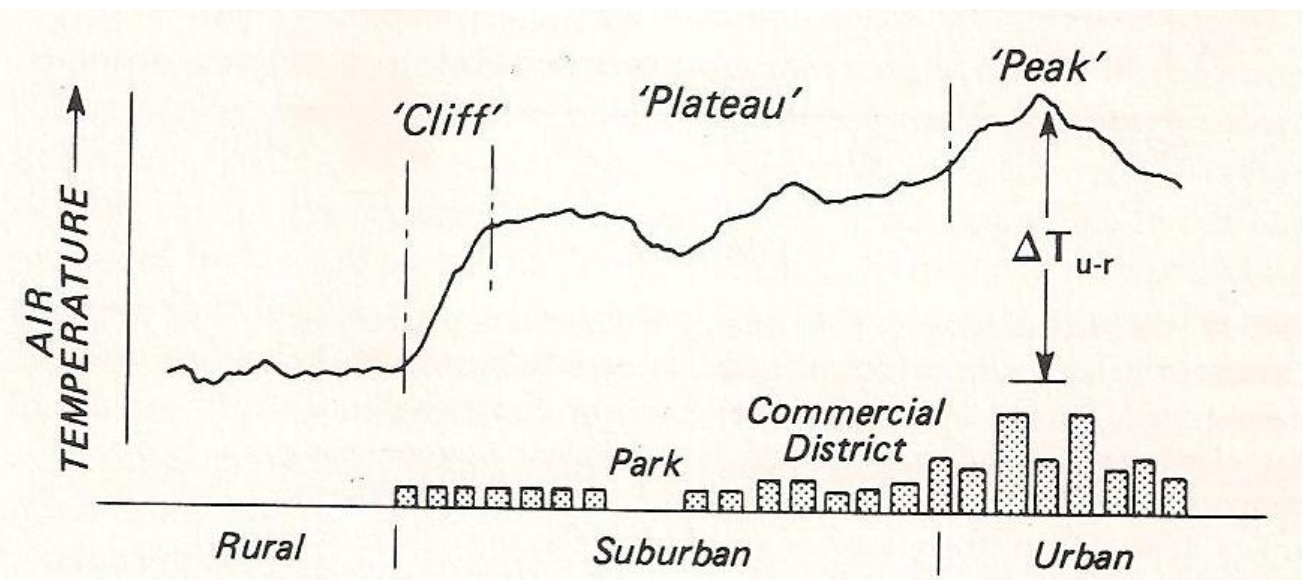

Figure 1: Generalized cross-section of a typical UHI (Oke, 1987)

The UHI phenomenon may occur during the day or during the night. Givoni (1998) mentioned that the largest elevations of the urban temperatures occur during clear and still-air nights. Under these conditions, temperature elevations of about $3-5^{\circ} \mathrm{C}$ are common, but elevations of about $8-10^{\circ} \mathrm{C}$ were also observed. Today, the majority of cities are around $2^{\circ} \mathrm{C}$ warmer than rural areas, and commercial and high density residential areas are hotter by 5 to $7^{\circ} \mathrm{C}$ (Bonan, 2002). There are some main parameters which influence the temperature increase in cities and play significant role on it. Therefore, UHI is caused by different factors that can be divided into two types: (1) meteorological factors, such as cloud cover, wind speed and humidity; (2) building factors, such as forms and height of buildings, building materials, and activities taking place in the buildings.

According to Landsberg (1981), a UHI is present in every town and city and is the most obvious climatic manifestation of urbanisation. Clearly higher urban temperatures seriously impact the electricity demand for air conditioning in buildings and increase smog production, as well as contribute to increased emission of pollutants from power plants, including sulphur dioxide, carbon monoxide, nitrous oxides and suspended particulates (Asimakopoulos et al., 2001).

Considering heavy construction, UHIs are a result of many factors, the most important of which are summarised by Oke et al. (1991):

1. Canyon radiative geometry contributes to decreasing the long-wave radiation loss from street canyons as a result of the complex exchange between buildings and the screened skyline. Infrared radiation is emitted from various buildings and street surfaces within the canyons. Buildings replace a fraction of the cold sky hemisphere with much warmer surfaces, which receive a high portion of the infrared radiation emitted from the ground and radiate back an even greater amount;

2. Thermal properties of materials may increase heat storage in the fabric of the city during the daytime and release the stored heat into the urban atmosphere after sunset. Furthermore, the replacement of natural soil or vegetation by materials, such as concrete and asphalt, typically used in cities reduces the potential to decrease ambient temperature through evaporation and plant transpiration; 
3. Anthropogenic heat is released by the combustion of fuels from either mobile or stationary sources, as well as by animal metabolism;

4. The urban greenhouse effect contributes to the increase in the incoming long-wave radiation from the polluted urban atmosphere. This extra radiative input to the city reduces the net radiative drain;

5. Canyon radiative geometry decreases the effective albedo of the system because of the multiple reflections of short-wave radiation by the canyon surfaces;

6. The reduction of evaporating surfaces in the city puts more energy into sensible heat and less into latent heat; and

7. There is reduced turbulent transfer of heat within streets.

\section{Shophouses In Kula Lumpur, Malaysia As Case Study}

Typically, shophouses consist of shops on the ground floor which open up to the public and which have residential accommodation upstairs. As a matter of fact, they are a combination of commercial and residential land uses (Figure 2). Therefore, there are two different types of land uses which of each has different function. In this way, shophouses are multi-functional (Figure 3). The functions of shops in downstairs are also various which can be divided into:

1. Food and beverage outlet;

2. Service provider;

3. Industrial activities; and

4. Community space.

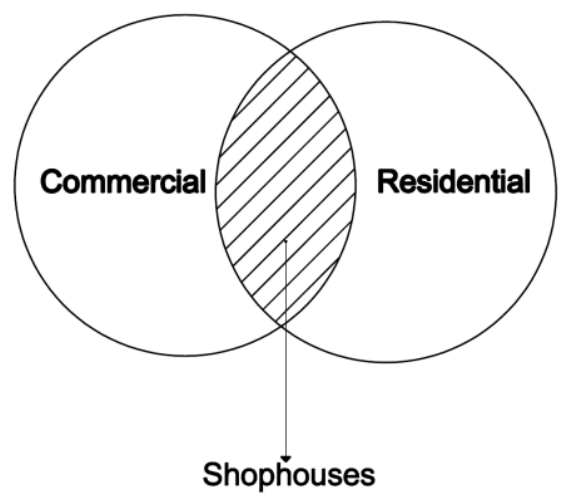

Figure 2: Combination of two different land uses 


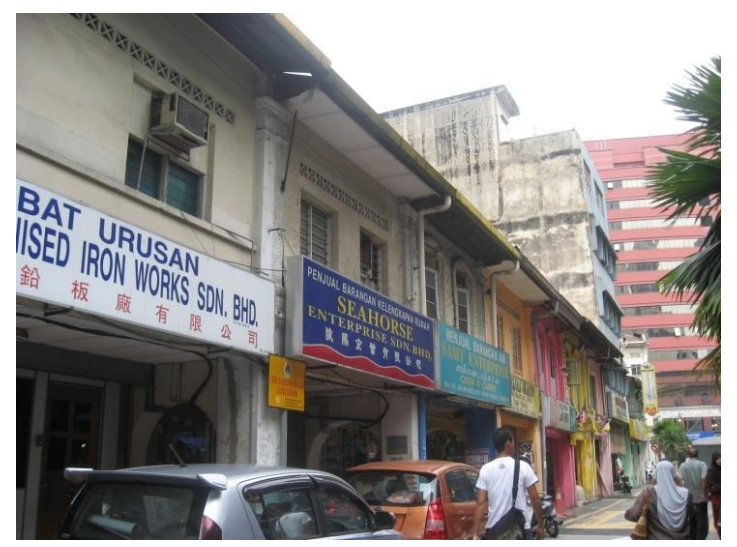

Figure 3: A row of shophouses with different function in downstairs

These different kinds of activities or functions have different impacts on UHI intensity. In restaurants, for example, producing higher rate of heat due to the cooking can increase the rate of anthropogenic heat which is the most significant factor on formation of UHI. In this case, different kinds of activities occur in shophouses must be considered and classified in order to study the UHI intensity.

This paper has selected a row of shophouses in the narrow street of Malayu (Figure 4 and 5). This street is located in the central part of the Kuala Lumpur which is the most important commercial activities occur in this area. In other word, it is the central business district (CBD). In general, around of study area has been surrounded by some high rises with commercial, administrative and services activities (Figure 6). In detail, various land uses and activities has surrounded this narrow street with higher levels of socialization (Figure 7) including monorail station on the east side (at the end of the street which is dead end) (Figure 8), bazaar on the north side of the area with higher production of anthropogenic heat (Figure 9) and it reaches to Lorong Tuanku Abdul Rahman street on the west side with a row of shophouses in both side of the street.
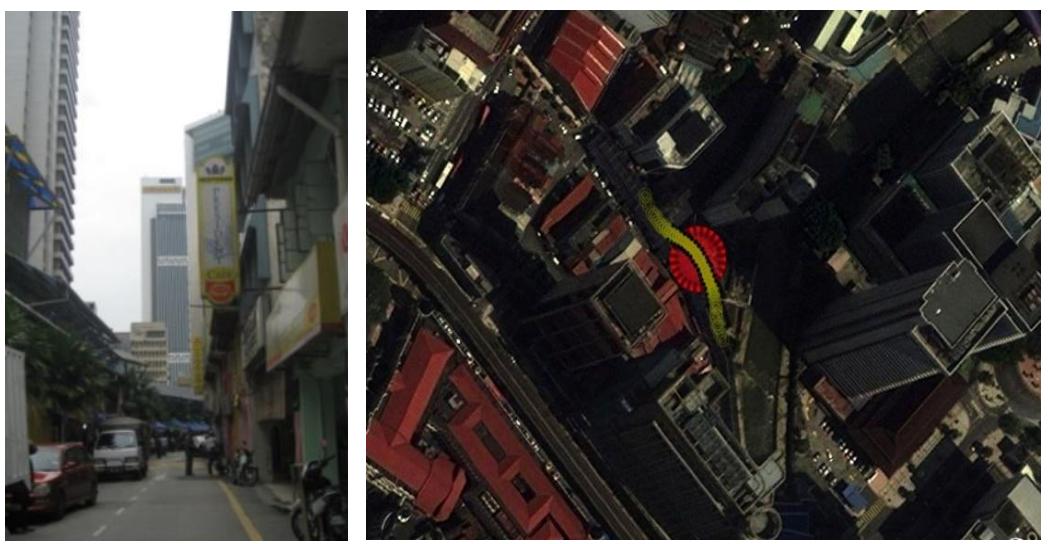

Figure 4: The study area, Melayu Street 


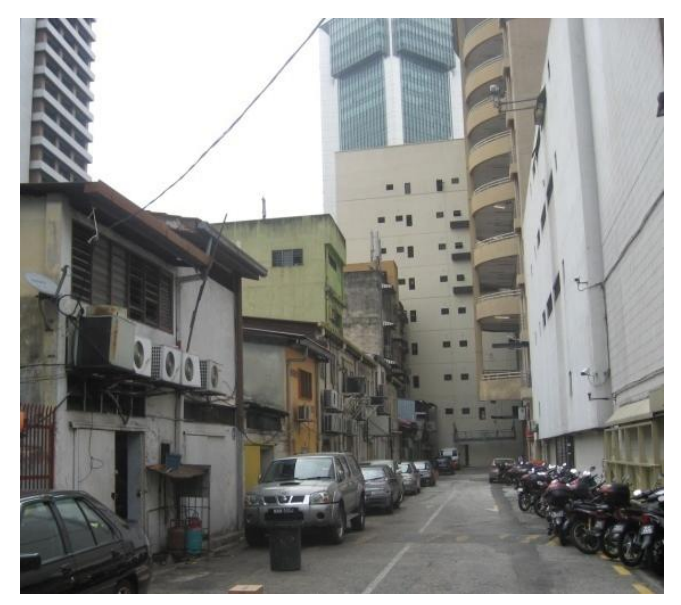

Figure 5: The backlane of Melayu Street
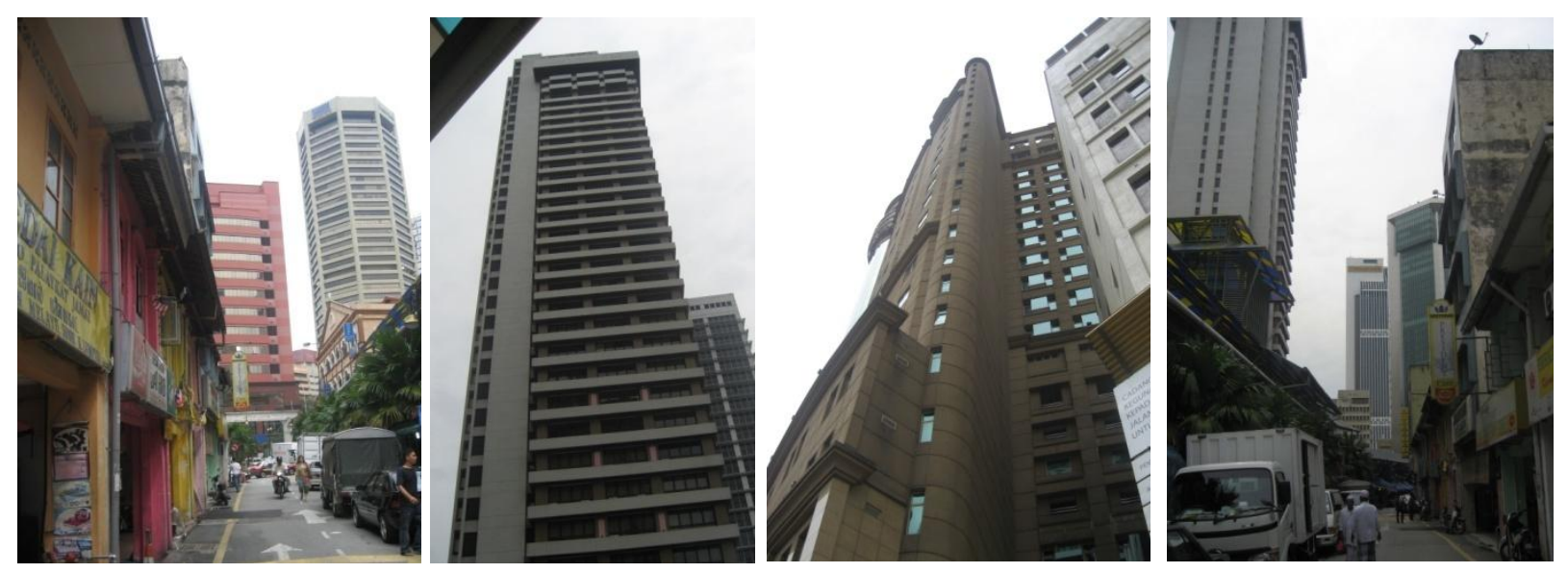

Figure 6: High rises surrounded the study area

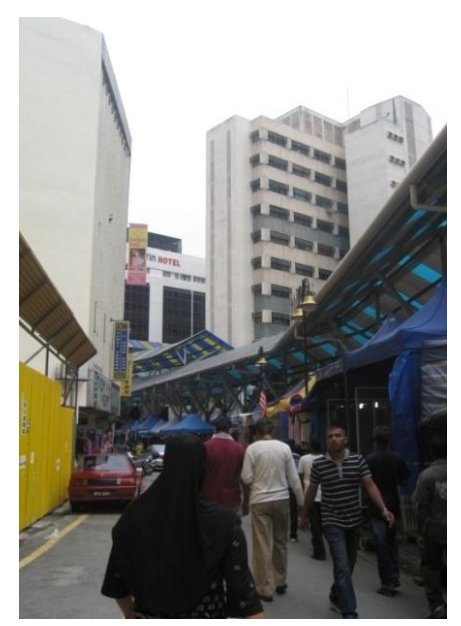

Figure 7: Socializing in Melayu Street 


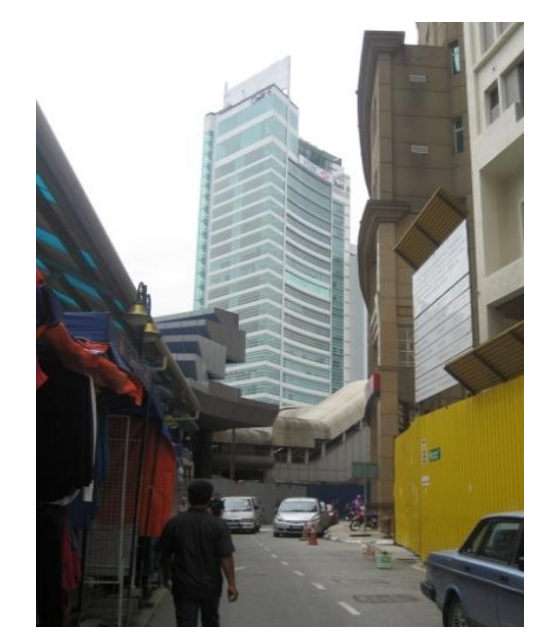

Figure 8: Monorail station at the end of Melayu Street

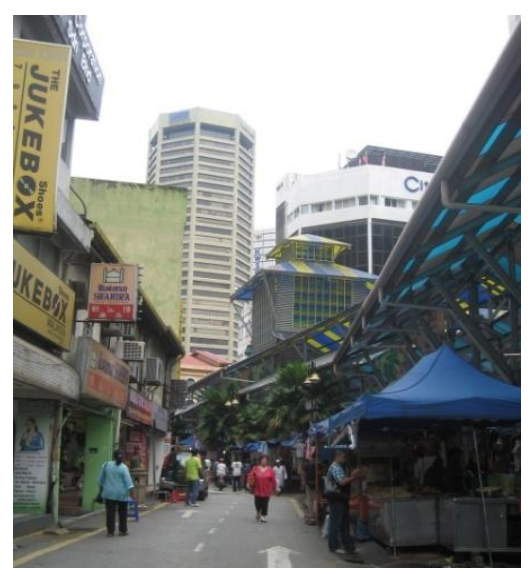

Figure 9: Bazaar opposite the study area with higher production of anthropogenic heat by cooking activities

Since the aim of this paper is to focus on the role of shophouses on formation of UHI, therefore this area has been chosen as the concentration of the activities, especially commercial activities, and socializing are in the higher level. In other hand, the most of selected shophouses have food and beverage outlet which by producing higher anthropogenic heat are able to increase the percentage of formation of UHI over this area. Moreover, cooking activates in bazaar, monorail station by evacuating large number of people and also high rises around the study area have doubled this problem. Therefore, this street has great potentials to form UHI and it is required to identify the radical causes of problems in order to mitigate UHI effects in this area. 


\section{Conceptual Framework: Enrgy Consumption Balance}

\subsection{Relation between Anthropogenic Heat and Building Factors and Formation of Urban Heat Island}

Urban areas are the sources of anthropogenic carbon dioxide emissions from the burning of fossil fuels for heating and cooling; from industrial processes; transportation of people and goods, and the like (Grimmond, 2007; Oke, 1981; Santamouris, 2001). Increased in pollutant sources both stationary (industrial) and non-stationary (vehicles) result in worsening atmospheric conditions (Roth 2002). The urban environment affects many climatological parameters. Global solar radiation is seriously reduced because of increased scattering and absorption (Santamouris, 2001). Many cities in the tropics experience weak winds and limited circulation of air which helps the accumulation of pollutants (Roth, 2002). The wind speed in the canopy layer is seriously decreased compared to the undisturbed wind speed and its direction may be altered. This is mainly due to the specific roughness of a city, to channelling effects through canyons and also to UHI effects (Santamouris, 2001). In addition, higher temperatures increase the production of secondary, photochemical pollutants and the high humidity contributes to a hazy atmosphere.

Gartland (2008) stated that, although anthropogenic heat, low wind speeds and air pollution in urban areas can contribute to UHI formation, there are two main reasons for formation of UHI which include:

1. Because of impermeable and watertight urban construction materials, moisture is not available to dissipate the sun's heat; and

2. Dark materials in concert with canyon-like configurations of buildings and pavement collect and trap more of the sun's energy. Temperatures of dark, dry surfaces in direct sun can reach up to $88^{\circ} \mathrm{C}$ during the day, while vegetated surfaces with moist soil under the same conditions might reach only $18^{\circ} \mathrm{C}$.

Rapid growth of urbanization is caused UHI due to many factors which Oke (1981) incorporated these causes into the following five categories, each of which represents change to the pre-urban environment brought about by urbanization:

1. Anthropogenic heat;

2. Air pollution;

3. Surface waterproofing;

4. Thermal properties of fabric; and

5. Surface geometry. 
1. Anthropogenic heat discharge in a city also contributes to the UHI effect. Sources of anthropogenic heat include cooling and heating buildings, manufacturing, transportation, and lighting. Human and animal metabolisms are also considered sources of artificial heat (Peterson, 1973). Heat from these sources warms the urban atmosphere by conduction, convection, and radiation. The contribution of anthropogenic heat to the urban energy balance is largely a function of latitude and season of the year. In a temperate city, for example, anthropogenic heat flux may be a significant component of the energy balance in winter, yet a negligible component in summer. In a polar settlement artificial heat flux may exceed solar heating year-round (Lee, 1984).

2. Air pollution, results from emissions of particulates, water vapour, and carbon dioxide from industrial, domestic, and automobile combustion processes. These atmospheric pollutants change the urban net all-wave radiation budget by: (1) Reducing the incident flux of short-wave (i.e. solar) radiation; (2) Re-emitting long-wave (i.e. infrared) radiation from the urban surface downward to where it is retained by the ground; and (3) Absorbing long-wave radiation from the urban surface, effectively warming the ambient air (Oke, 1987). Lee (1984) estimated that urbanrural differences in downward long-wave radiation flux may be of the order of 10 percent, depending on the city population and the presence of heavy industry.

3. Surface waterproofing, refers to the predominance of impermeable surface in urban areas. Building and paved streets quickly shed precipitation into catchment basins, creating an evaporation deficit in the city. Conversely, in rural areas exposed soils and natural vegetation retain water for evapotranspirational cooling. A day urban surface cover enhances sensible heat transfer and suppresses latent heat flux, whereas moist rural surface suppress sensible heat transfer and enhance latent heat flux.

4. The forth factor contributing to the formation of UHIs relates to the thermal properties of the urban fabric. The heat capacity, and consequently thermal inertia, of urban construction materials such as concrete and asphalt is greater than that of natural materials found in rural environments. A greater heat capacity means that urban materials absorb and retain more solar radiation than do rural soils and vegetation. Reflection of short-wave solar radiation is also affected by the properties of the urban fabric. Urban albedos are, on average, 5-10 percent lower than rural values (Lee, 1984). This contributes to the greater diurnal absorption of short-wave radiation in urban areas.

5. The complex geometry of urban surfaces influences air temperatures in two ways. First, increased friction created by a rough urban surface (as compared to a smooth rural surface) reduces horizontal airflow in the city. Mean annual wind speeds within cities are approximately 30-40 percent lower than mean annual wind speeds in the countryside (Lee, 1984). Warm air stagnates in the urban canyons unless ventilated by cool rural air. Lower wind speeds in the city also inhibit evaporational cooling. And second, the complex geometry of the urban surface changes the urban radiation budget. During the day vertical canyon walls trap (i.e. reflect and absorb) short-wave radiation. Night-time losses of infrared energy are also retarded due to the decreased sky view below roof level. Rural surfaces, on the 
other hand, are comparatively smooth and therefore experience greater nocturnal radiative flux divergence than complex urban surface.

Anthropogenic heat is generated by human activity and comes from many sources, such as buildings, industrial processes, cars and even people themselves (Gartland, 2008). Urban centres (commercial centres) tend to have higher energy demands than surrounding areas as a result of higher production of anthropogenic heat. Though the UHI effect reduces the need for heating in the winter, this is outweighed by the increased demand for airconditioning during the summer months (Landsberg, 1981), which in turn causes increased local and regional air pollution through fossil-fuel burning electric power generation. The pollution created by emissions from power generation increases absorption of radiation in the boundary layer (Oke, 1982) and contributes to the creation of inversion layers. Inversion layers prevent rising air from cooling at the normal rate and slow the dispersion of pollutants produced in urban areas (Sahashi et al., 2004). To determine how much anthropogenic heat is produced in any region, all energy use (commercial, residential, industrial and transportation) must be tailed. The sum is then divided by the region's area to enable comparisons of different cities to be made (Gartland, 2008).

In developed countries, such as Malaysia, where concerted action is being taken on UHIs, the main concern is on the large increase in power consumption in urban areas to cool down buildings, with additional air-conditioners or a heavier usage of existing air-conditioners. Higher air temperatures also mean that the air quality deteriorates as a result of increased ozone and pollution.

\subsection{Energy Consumption Balance}

As discussed previously, there is no single cause of the UHI. In fact, many factors combine to warm cities. Gartland (2008) listed urban characteristics contributing to UHI formation in Table 1 which these characteristics can be stored into five main causes of UHI formation:

1. Increased anthropogenic heat;

2. Reduced evaporation;

3. Increased heat storage;

4. Increased net radiation; and

5. Reduced convection.

Table 1: Urban and suburban characteristics important to UHI formation and their effect on the energy balance of the earth's surface (Gartland, 2008)

\begin{tabular}{|l|l|}
\hline Characteristic contributing to UHI formation & Effect on the energy balance \\
\hline Lack of vegetation & Reduced evaporation \\
\hline Widespread use of impermeable surfaces & Reduced evaporation \\
\hline Increased thermal diffusivity of urban materials & Increased heat storage \\
\hline Low solar reflectance of urban materials & Increased net radiation \\
\hline Urban geometries that trap heat & Increased net radiation \\
\hline Urban geometries that slow wind speeds & Reduces convection \\
\hline Increased levels of air pollution & Increased net radiation \\
\hline Increased energy use & Increases anthropogenic heat \\
\hline
\end{tabular}


The anthropogenic heat interacts with its environment in a complex manner. To understand and simplify the complexity, Oke (1988) has suggested an equation called the "energy balance" which the heat generated by and contained in an area could be calculated by this equation (equation 1 ) as below:

$\mathrm{Q}^{*}+\mathrm{Q}_{\mathrm{F}}=\mathrm{Q}_{\mathrm{H}}+\mathrm{Q}_{\mathrm{E}}+\Delta \mathrm{Q}_{\mathrm{S}}+\Delta \mathrm{Q}_{\mathrm{A}}$

Where,

$\mathrm{Q}^{*}=$ the net all-wave radiation

$\mathrm{Q}_{\mathrm{F}}=$ the anthropogenic heat release

$\mathrm{Q}_{\mathrm{E}}=$ the turbulent sensible

$\mathrm{Q}_{\mathrm{H}}=$ turbulent latent heat flux densities

$\Delta \mathrm{Q}_{\mathrm{s}}=$ the sensible heat storage

$\Delta \mathrm{Q}_{\mathrm{A}}=$ the net heat advection

\section{- $\quad$ Net Radiation}

As shown in equation (2), net radiation encompasses four separate radiation process taking place at the Earth's surface (Gartland, 2008):

Net radiation = Incoming solar - Reflected solar + Atmospheric radiation - surface radiation

Where,

Incoming solar $=$ the amount of energy radiating from the sun

Reflected solar $=$ the amount of solar energy that bounces off a surface, based on the solar reflectance of the material Atmospheric radiation $=$ heat emitted by particles in the atmosphere, such as water vapour droplets, clouds, pollution and dust

Surface radiation $=$ heat radiated from a surface itself

The net all-wave radiation could then be calculated as the difference in between the incoming and outgoing parts (Brotzge and Crawford, 2003; Christen and Vogt, 2004). The incoming short wave solar radiation was reported to be attenuated due to the heavy smoke over urban areas (Sang et al., 2000; Oke, 1988). The attenuation has been reported to be as high as $33 \%$ in some cases (Stanhill and Kamala, 1995) and has also been reported as a cause of urban cool island (Sang et al., 2000). In some other areas, on the other hand, the attenuation has not been observed (Christen and Vogt, 2004). It is reported that the attenuation of incoming short wave radiation is compensated by albedo related drop in outgoing shortwave radiation and enhancement of incoming long wave radiation is compensated by an increase in outgoing long wave radiation due to the high surface temperature emittance. It was reported that most of the attenuated part is diffused and received back and the net difference between the urban and rural areas may not be more than 5\% (Oke, 1982, 1988). 


\section{- Anthropogenic heat $\left(Q_{F}\right)$}

Anthropogenic heat represents the heat generated from stationary and mobile sources of an area. It is reported that the $\mathrm{Q}_{\mathrm{F}}$ must either be converted to radiations, sensible heat flux or latent heat flux or is stored (Christen and Vogt, 2004). This component has been modelled as the sum of heat generated by the buildings, vehicles and people (Sailor and Lu, 2004; Grimmond, 1992) or as the residual of other terms (Christen and Vogt, 2004).

Oke (1988) reported that anthropogenic heat release could be related to the population and its per capita energy use. Taha (1997) reported that the anthropogenic heat has smaller effect than albedo and vegetation cover, and is negligible in commercial and residential areas. Offerle et al. (2006), on the other hand, have considered it as a significant input in winter. It seems that depending on the area and its energy use the term could be significant or negligible and it could have varying diurnal, seasonal or even weekly trends.

\section{- Turbulent Heat Fluxes}

Turbulent heat fluxes comprise of the sensible and the latent heat flux, which could be directly derived from eddy correlation, measured using appropriate equipments. The heavily built urban areas are reported to be responsible for increased sensible heat flux which is reported to vary as per the built surface (Oke, 1988). The intensity of latent heat flux, on the other hand, varies from situation to situation as concluded by Hafner and Kidder (1999). Grimmond (1992) described the latent heat flux as the largest portion in the Surface Energy Balance (SEB) while Masson (2000) has neglected it in his proposed town energy balance scheme. Although, it is likely that the latent heat flux will be low in an urbanized area due to decreased vegetation, it could be high in vegetated parts of the city. The study conducted by Suckling (1980) reported a Bowen Ratio, sensible-heat-flux-to-latent-heat flux ratio, of up to $98 \%$ for a suburban lawn. It was reported that the turbulent heat fluxes vary with respect to the $\mathrm{Q}^{*}$ (Arnfield and Grimmond, 1998; Offerle et al., 2006). Thermal admittance and ground moisture availability are reported to be other important factors in quantifying the turbulent heat fluxes (Oke, 1988).

\section{- Storage Heat Flux}

Christen and Vogt (2004) reported that due to the complicated configuration of surface materials, orientations and their interactions, the direct measurement of storage heat flux in an urbanized area is almost impossible. The term is, therefore, usually modeled or determined as the residual of the SEB equation. It is reported that an increase in the net all-wave radiation directly increases the stored heat flux. Grimmond (1992) found an increase of around $60 \%$ in the monthly averaged day-time ratio of stored heat flux to the net all-wave radiation with an increase of net all-wave radiation.

\section{- $\quad$ Net Heat Advection $\left(\Delta \mathbf{Q}_{\mathrm{A}}\right)$}

Net heat advection could be referred to as the inaccurate measurement due to spatial gradient in temperature, humidity and wind. It is suggested that the effects of advection could be negligible provided that caution has been taken in deciding the measurement height (Christen and Vogt, 2004). 
The preceding concept highlights that how energy is transformed to and from the Earth's surface. The energy balance equation is based on the first law of thermodynamics, which states that energy is never lost. For a surface on the Earth, this means that all of the energy absorbed by the surface through radiation or from anthropogenic heat goes somewhere. Either it warms the air above the surface, is evaporated away with moisture or is stored in the material as heat. Other statistical data show that the amount of energy consumed by cities for heating and cooling offices and residential buildings has increased significantly in the last two decades. Emmanuel (1995) has shown the rate of energy consumption of three countries, US, U.K. and Sri Lanka, in Table 2. A comparison of energy-use patterns between a developed country like the US and a developing country like Sri Lanka shows that transportation and activities within buildings consume a considerable share of energy in both cases.

Table 2: Patterns of commercial energy consumption (Emmanuel, 1995)

\begin{tabular}{|l|c|c|c|}
\hline \multirow{2}{*}{ Activity } & \multicolumn{3}{|c|}{ Energy Consumption (\% of total country needs) } \\
\cline { 2 - 4 } & US & U.K. & Sri Lanka \\
\hline Industries & 41.2 & 32.0 & 9.9 \\
\hline Transportation & 21.0 & 18.0 & 16.4 \\
\hline Building Energy needs & 28.0 & 48.0 & 67.0 \\
\hline Agriculture/other & 7.7 & 2.0 & 6.7 \\
\hline
\end{tabular}

Increased anthropogenic heat has a direct effect on building energy consumption. In fact, higher production of anthropogenic heat leads to increase the electricity demand for cooling and the production of carbon dioxide and other pollutants. Therefore, it can be concluded that an increasing the production of anthropogenic heat, which leads to raised temperatures and generates an UHI that provides a warm air canopy over the city. Consequently, it causes significantly increased energy consumption to heat and cool buildings. This process is summarised in Figure 10.

This paper has tried to develop a concept to show the conflict between anthropogenic heat and building factors can affect energy balance. This paper highlights energy consumption, anthropogenic heat and building factors as the key components. According to Bridgman et al. (1995), replacing grass, soil and trees with asphalt, concrete and glass; the rounded, soft shapes of trees and bushes with blocky, angular buildings and towers; artificial heat from buildings, air conditioners, industry and automobiles; efficiently disposing of precipitation in drains, sewers and gutters, preventing surface infiltration; and emitting contaminants from a wide range of sources, which with resultant chemical reactions, can create an unpleasant urban atmosphere, higher production of anthropogenic heat and then UHI intensity increased. 


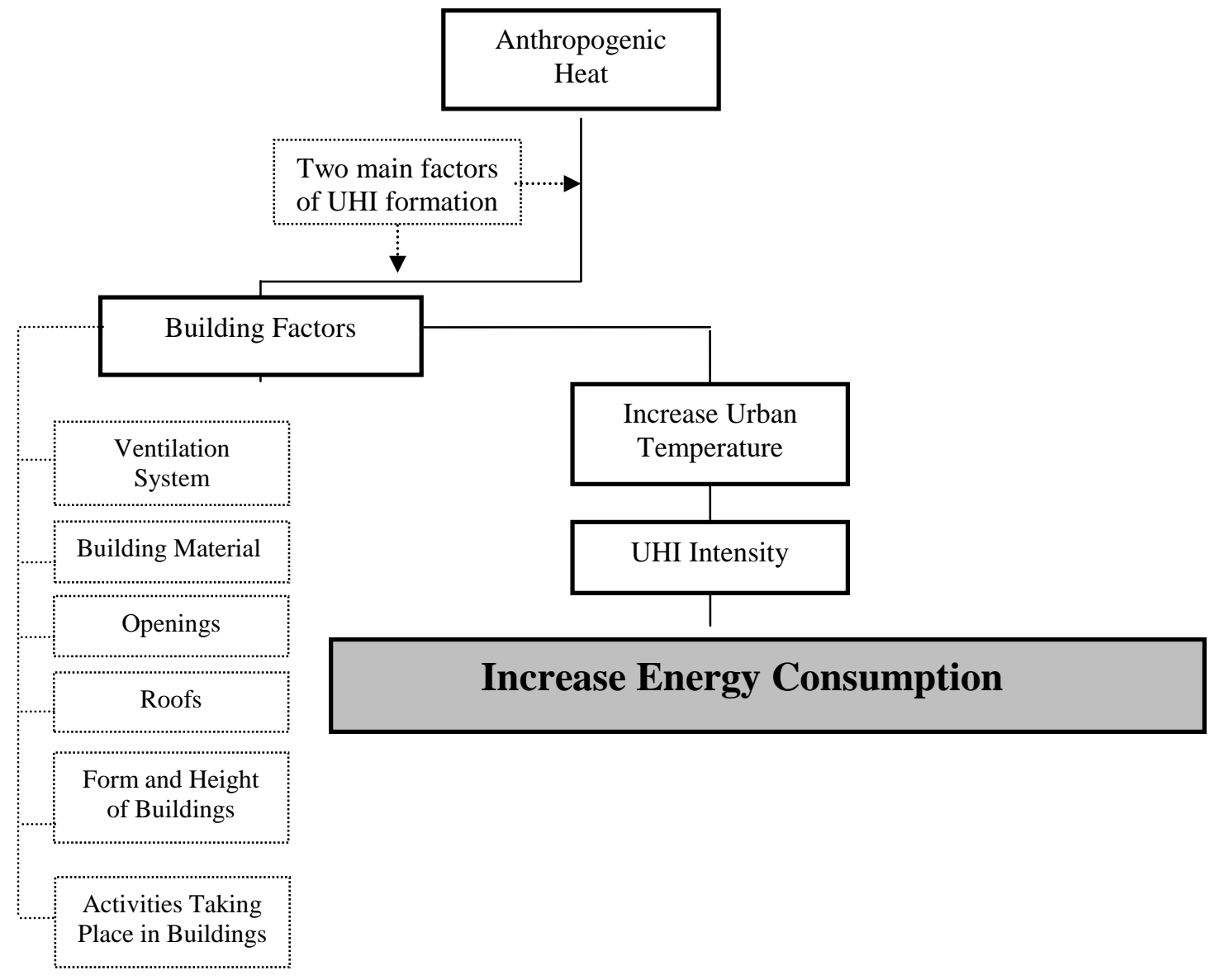

Figure 10: The process of increasing energy consumption

Compiling the three key components into a concept is meaningful in reducing UHI effects and achieving energy consumption balance. The conflict between these three key components is presented in the concept shown in Figures 11 and 12.

In Figure 11, the shaded area represents the UHI intensity. A greater conflict between anthropogenic heat and building factors causes higher UHI intensity. With increasing UHI intensity, energy consumption loses its balance, while Figure 12 shows that by mitigating UHI effects, energy consumption balance can be achieved.

This process can be described in the following way:

$$
\begin{aligned}
& \mathrm{UHI} \downarrow=\mathrm{ECB} \\
& \mathrm{UHI} \downarrow=\mathrm{AH} \downarrow+\mathrm{BF} \downarrow \\
& \mathrm{AH} \downarrow+\mathrm{BF} \downarrow=\mathrm{ECB}
\end{aligned}
$$

Where,

UHI is the urban heat island ( $\downarrow$ decrease), ECB is the energy consumption balance, AH is the anthropogenic heat, BF is building factors. Therefore, by decreasing anthropogenic heat and building factors, mitigation of UHI effects is achievable. 


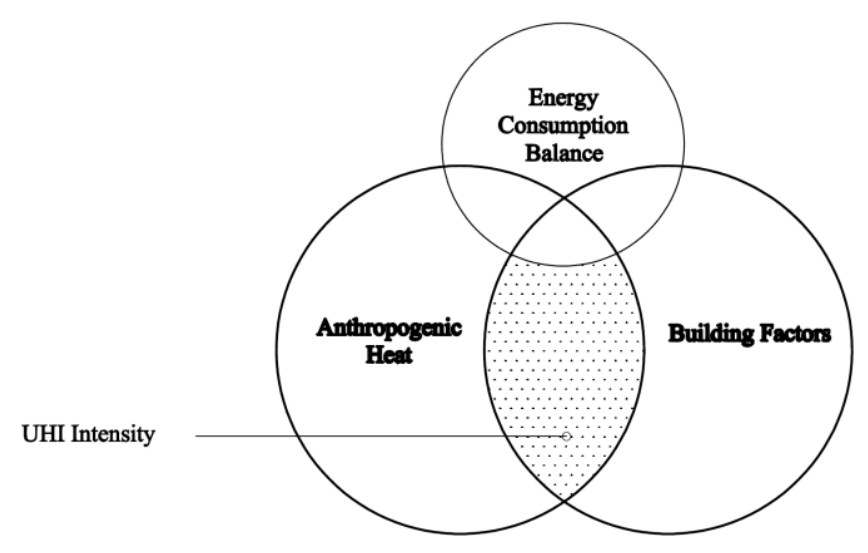

Figure 11: Conflict between anthropogenic heat and building factors, creation of UHI and its effect on energy consumption balance

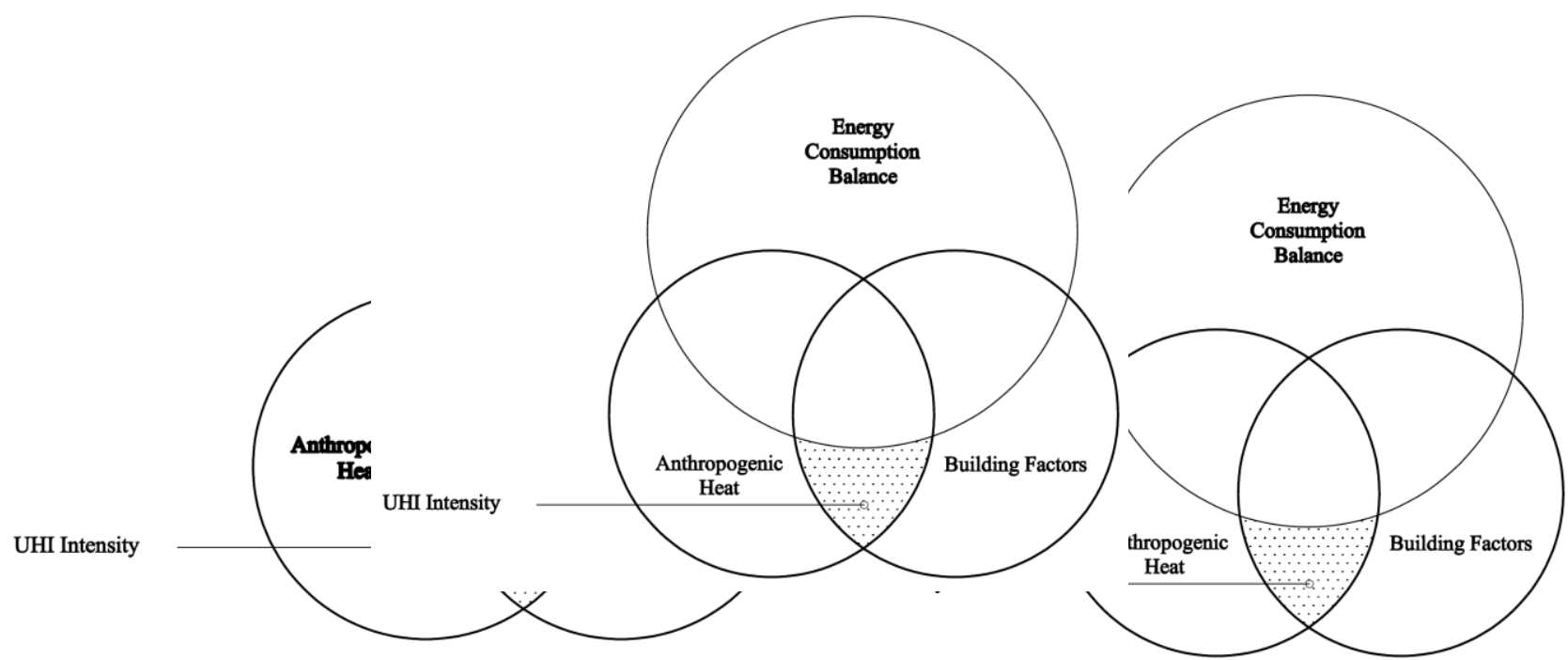

Figure 12: Mitigation of UHI has direct effect on energy consumption balance

Although decreasing the anthropogenic heat is depend on building factors, an optimal and realistic solution is to focus on building factors, such as natural ventilation, surface materials and landscape or vegetation covers to decrease UHI intensity and create energy consumption balance.

$$
\begin{aligned}
& \mathrm{ECB}=\mathrm{MEC}+\mathrm{LEC}+\mathrm{NVEC} \\
& \text { MEC }=\text { LEC }=\text { NVEC } \\
& \text { Where, }
\end{aligned}
$$

MEC is the amount of reflectivity and emissivity of surface materials, LEC is the amount of appropriate landscape or vegetation covers; NVEC is the appropriate amount of wind introduced into a built environment; an appropriate solution is adequate vegetation, natural ventilation and high albedo materials, which results in an acceptable impact on energy consumption balance. 
Under such circumstances, a balanced urban environment can be created (Figure 13). This means that adding natural ventilation, vegetation covers and high albedo and high emissivity materials in buildings can reduce UHI effects and balance energy consumption. This will be described in the next section.

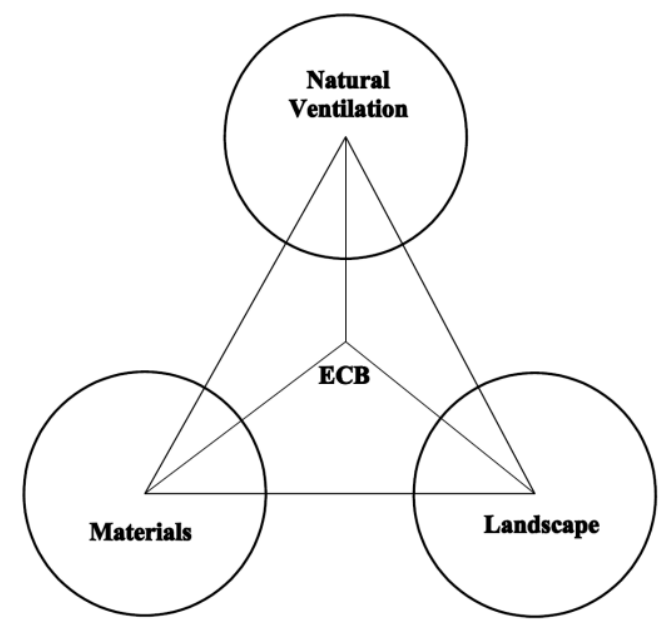

Figure 13: Achieve energy consumption balance by providing balance with natural ventilation, high albedo materials and vegetation covers

\section{Mitigation Of Urban Heat Island Effects: Achieving Energy Concumption Balance In Kuala Lumpur Shophouses}

The reduction of the energy consumption of buildings by combining techniques to improve the thermal quality of the ambient urban environment with the use of up-to-date alternative passive cooling and lighting techniques can partly decrease these kinds of environmental problems.

In study area, production of anthropogenic heat from shophouses due to the cooking and cooling systems lead to higher air temperature and less intensive winds are causes of UHI effects. In addition, inappropriate ventilation systems (Figure 14), high density surrounded with high rises and inappropriate materials such as nonreflective and low albedo materials (Figure 15) in shophouses in study area can directly affect UHI formation. 


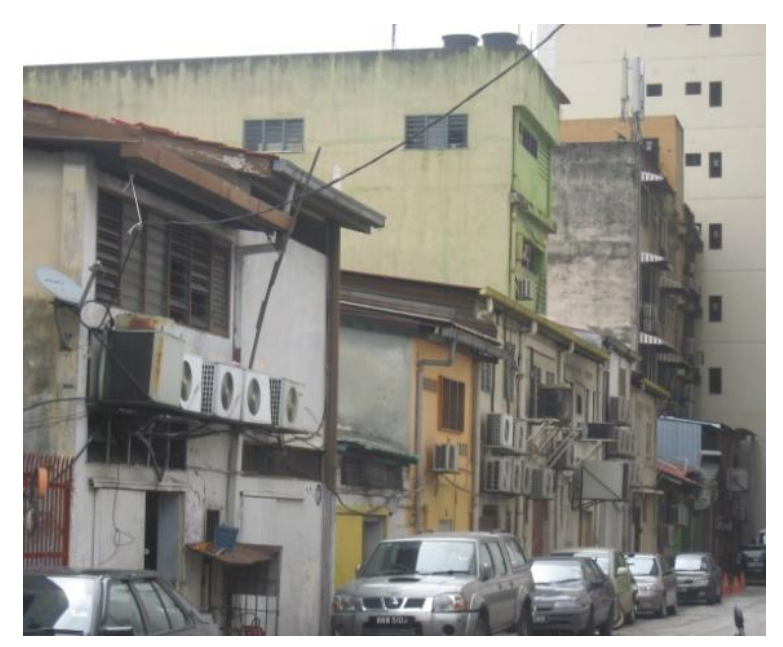

Figure 14: The lack of appropriate ventilation systems in shophouses

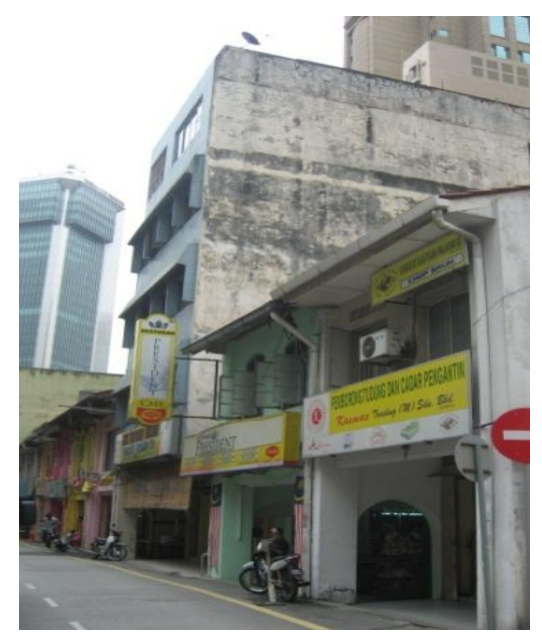

Figure 15: Using inappropriate materials such as concrete in shophouses

If proper interventions are implemented in the shophouses, better climate conditions will be achieved when serious overheating problems occur. A large number of air conditioning appliances leads to increased cooling loads and to over-consumption of electric energy, which also increase peak energy demand and creates failures in the energy transport network. Energy saving techniques that can be applied in a building includes two kinds of strategies that can be divided into urban elements and building elements strategies. The first strategy includes the energy conservation methods, which involve application of some strategies in urban areas, while the second method includes strategies for buildings. This paper focuses on three main strategies which will be discussed in next section.

The combination of these strategies will provide the best possible energy saving solution. According to the above considerations these strategies are described in the following sections. 


\subsection{Promoting Natural Ventilation}

Natural ventilation is the most effective passive cooling technique that can provide cooling during both day and night, while night ventilation is a very effective strategy in hot climates (Asimakopoulos et al. 2001). Some strategies for buildings can provide natural ventilation and save energy. Therefore, this paper recommends some strategies to achieve this aim:

1. Natural ventilation by arranging the openings in buildings to face the prevailing wind can provide efficient natural ventilation and create a healthy indoor air quality.

2. Natural ventilation by ventilated roofs eliminates overheating.

3. Variation in building height can create better wind at higher levels if differences in building heights between rows are significant.

4. Building orientation with adequate gaps is useful for good airflow.

5. Increasing building permeability by providing void decks or pilots at ground level or at mid-span.

\subsection{Using Appropriate Materials on External Surfaces of the Buildings}

An increase in the surface albedo has a direct impact on the energy balance of a building. Cities and urban areas in general are characterised by a relatively reduced effective albedo as a result of two mechanisms (Santamouris, 2001):

(1) Darker buildings and urban surfaces absorb solar radiation.

(2) Multiple reflections inside urban canyons significantly reduce the effective albedo.

As Asimakopoulos et al. (2001) stated, numerous studies have been performed to evaluate the direct effects of albedo change and demonstrate the benefits of using reflective surfaces. In all cases, the roof temperatures are significantly reduced, but the degree to which the cooling load decreases depends on the structure of the roof and on the overall thermal balance of the building. Surface materials with a high albedo index to solar radiation reduce the amount of energy absorbed through building envelopes and urban structures and keep the surface cooler. Building materials can be divided into pavement materials, roof materials and building envelopes.

Therefore, this paper recommends using reflective materials on external surface of building to reduce UHI effects and improve the urban environment.

\subsubsection{Using High Albedo Materials on Building Surfaces}

A material with high albedo can reduce the solar heat gain during the daytime. The surface temperature of the material is lower than that of a material with low albedo. Because the urban ambient temperature is associated with the surface temperatures of the building façade, lower surface temperature can obviously decrease the ambient air temperature and eventually contribute to better urban thermal environment. 


\subsubsection{Using White Pavement Instead of Asphalt}

Asphalt temperature can reach $63^{\circ} \mathrm{C}$ and white pavements only reaches $45^{\circ} \mathrm{C}$ (Santamouris, 2001). Lower surface temperatures contribute to decreasing the temperature of the ambient air because the heat convection intensity from a cooler surface is lower. Such temperature reductions have a significant impact on cooling energy consumption in urban areas.

\subsubsection{Using Cool Roofs}

Cool roofs reduce building heat-gain, create saving air conditioning expenditures, enhance the life expectancy of both the roof membrane and the building's cooling equipment, improve thermal efficiency of the roof insulation, reduce the demand for electric power, reduce resulting air pollution and greenhouse gas emissions, provide energy savings and mitigate UHI effects.

\subsection{Providing Appropriate Landscape}

Providing an appropriate landscape in building can contribute to energy consumption reduction. The impact of an appropriate landscape around a building on energy consumption and surrounding temperature regime is very important. Landscaping the surrounding area is a basic criterion to improving the external climatic conditions. As mentioned by Asimakopoulos et al. (2001), shading from trees can:

(1) Significantly decrease the energy required for cooling;

(2) Decrease the rate of heat convection inside buildings because of shaded surfaces that have a lower temperature; and

(3) Decrease the radiation exchange of the wall with the sky.

Sailor (1994) considers that the low evaporative heat flux in cities is the most significant factor in the development of an UHI. When vegetation is placed on urban surfaces, thermal balances can shift to new conditions that are closer to the cooler conditions of rural areas. It is estimated that $1460 \mathrm{~kg}$ of water is evaporated from an average tree during a sunny day, which consumes about $860 \mathrm{MJ}$ of energy; this offers a cooling effect outside a building that is equal to five average air conditioners (Santamouris, 2001). Furthermore, to reduce energy consumption, various types of trees and vegetation covers in different parts of the buildings must be considered. Therefore, this paper recommends using green spaces in vertical and horizontal layers. 


\subsubsection{Vertical Green Spaces}

Green spaces in some parts of buildings that provide natural ventilation or appropriate landscapes in different layers or floors of buildings with a multiuse function can significantly decrease the energy required to cool buildings.

\subsubsection{Horizontal Green Spaces}

Green spaces on roofs absorb heat, decrease the tendency towards thermal air movement and filter air movement. Through the daily dew and evaporation cycle, plants on vertical and horizontal surfaces are able to cool cities. In the process of evapotranspiration, plants use heat energy from their surroundings when evaporating water.

\section{Conclusion}

In general, the effects of various land uses and activities around given area on formation of thermal mass over them cannot be denied. Existing high rises surrounded the study area, monorail station on the east side, bazaar on the north side of the area, socializing and traffics on the narrow streets can also increase the percentage of UHI formation. Therefore, shop-houses not only can be affected UHI through the higher production of anthropogenic heat, but also surrounded activities and land uses have their own impacts on it.

Therefore, an effort must be made to reduce energy use and to promote green energies, particularly in the building sector. Energy balance can be achieved by minimising energy demand, rational energy use, recovering heat and using more green energies. This paper was a step towards achieving that goal. The adoption of green or sustainable approaches to the way in which society is run is seen as an important strategy in finding a solution to the energy problem. As discussed in this paper, one of the most important factors that increase energy use is the formation of UHIs. Therefore, this paper considers the effects of UHI and by recognising them, proposes beneficial solutions that can lead to energy consumption balance.

\section{References}

Arnfield A. J. and Grimmond C.S.B. (1998) An urban canyon energy budget model and its application to urban storage heat flux modeling. Energy and buildings, 27: 61-68.

Asimakopoulos D.N, Assimakopoulos V.D., Chrisomallidou N., Klitsikas N., Mangold D., Michel P., Santamouris M. and Tsangrassoulis A. (2001). Energy and Climate in the Urban Built Environment, M. Santamouris (Ed.) London, James \& James Publication.

Bonan G. (2002). Ecological Climatology, Camberidge University Press.

Brotzge J.A. and Crawford K.C. (2003) Examination of the surface energy budget: A comparison of eddy correlation and Bowen ratio measurement systems. Journal of Hydrometeorology, 4: 160-178. 
Bridgman H., Warner R. and Dodson J. (1995) Urban Biophysical Environments. Melbourne and New York: Oxford University Press.

Christen A. and Vogt R. (2004) Energy and radiation balance of a central European city. International Journal of Climatology, 24: 1395-1421.

Emmanuel M.R. (2005) An Urban Approach to Climate-Sensitive Design; Strategies for the Tropics, London, Spon Press.

Emmanuel M.R. (1995) Energy Conscious Urban Design Guidelines for Warm Humid Cities: Strategies for Colombo, Sri Lanka, Journal of Architecture and Planning Research, 12(1): 58-75.

Gartland L. (2008) Heat islands: understanding and mitigating heat in urban areas. London, Earthscan Press.

Givoni B. (1998) Climate Considerations in Building and Urban Design, Canada, John Wiley \& Sons.

Grimmond S. (2007) Urbanization and Global Environmental Change: Local Effects of Urban Warming. Cities and Global Environmental Change, 83-88.

Grimmond S. (1992) The suburban energy balance: Methodological considerations and results for a mid latitude west coast city under winter and spring conditions. International Journal of Climatology, 12: 481-497.

Hafner J. and Kidder S.Q. (1999) Urban heat island modelling in conjunction with satellite-derived surface/soil parameters. Journal of Applied Meteorology, 38: 448-465.

Landsberg E.H. (1981) The Urban Climate. Maryland, Academic Press.

Lee D.O. (1984) Urban Climates. Progress in Physical Geography, 8(4): 1-31.

Masson V. (2000) A physically based scheme for the urban energy budget in atmospheric models. Boundary Layer Meteorology, 94: 357-397.

Offerle B., Grimmond S., Fortuniak K., Klysik K. and Oke T.R. (2006) Temporal variations in heat fluxes over a central European City Centre. Theoretical and Applied Climatology, 84: 103-115.

Oke T.R., Johnson G.T., Steyn D.G. and Watson I.D. (1991) Simulation of Surface Urban Heat Islands Under Ideal Conditions at Night- Part 2: Diagnosis and Causation. Boundary Layer Meteorology, 56: 339-358.

Oke T.R. (1988) The urban energy balance. Progress in Physical geography, 12: 471-508.

Oke T.R. (1987) Boundary Layer Climates (2an edn.), New York, Methuen and Co. Ltd.

Oke T.R. (1981) Canyon Geometry and the Nocturnal Urban Heat Island: Comparison of Scale Model and Field Observations. Journal of Climatology, 1: 237-254.

Oke T.R. (1982) The Energetic Basis of the Urban Heat Island. Quarterly Journal of the Royal Meteorological Society, 108(455): 1-24.

Peterson J.T. (1973) The Climate of Cities: A Survey of Recent Literature. IN: McBoyle G. (ed.), Climate in Review, 264-285.

Roth M. (2002) Effects of Cities on Local Climates, Proceedings of Workshop of IGES/APN Mega-City Project, 2325 January 2002, Kitakyushu Japan.

Sahashi K., Hieda T. and Yamashita E. (2004) Nitrogen-Oxide Layer over the Urban Heat Island in Okayama City. Atmospheric Environment, 30(3): 531-535. 
Sailor D.J. and Lu L. (2004) A top-down methodology for developing diurnal and seasonal anthropogenic heating profiles for urban areas. Atmospheric Environment, 38: 2737-2748.

Sailor D.J. (1994) Sensitivity of Coastal Meteorology and Air Quality to Urban Surface Characteristics. Preprints of the Eighth Joint Conference on the Applications of Air Pollution Meteorology, American Meteorological Society, Boston, MA, 8, pp. 286-293.

Sang J., Liu H. and Liu H. (2000) Observational and numerical studies of wintertime urban boundary layer. Journal of Wind Engineering and Industrial Aerodynamics, 87: 243-258.

Santamouris M. (2001) Energy and Climate in the Urban Built Environment. London, James \& James Publication.

Stanhill G. and Kalma J.D. (1995) Solar dimming and urban heating at Hong Kong. International Journal of Climatology, 15: 933-941.

Suckling P.W. (1980) The energy balance microclimate of a suburban lawn. Journal of Applied Meteorology, 19: 606- 608.

Taha H. (1997) Urban climates and heat islands: Albedo, evapotranspiration, and anthropogenic heat. Energy and Buildings, 25: 99-103. 